\title{
Resenha
}

\section{Estatística para quem não gosta de números ${ }^{1}$}

\section{Statistics for those who don't like numbers}

\author{
Alexsandro Luiz de ANDRADE $^{2}$ \\ João Fernando Rech WACHELKE
}

A estatística permite a pesquisadores de diversas áreas do conhecimento o emprego de técnicas sofisticadas para lidar com os dados da realidade empírica. Assim, trata-se de uma ferramenta poderosa, capaz de caracterizar relações entre variáveis de modo preciso e com critérios compartilhados pela comunidade científica.

Contudo, embora a grande maioria dos cursos brasileiros de psicologia inclua em seu currículo disciplinas de estatística, frequentemente ela é ensinada de modo clássico, a partir de livros que enfocam cálculos e provas realizadas em papel. Não raro são adotados livros e exercícios de estatística sem qualquer relação com ciências humanas ou problemas de pesquisa referentes a fenômenos psicológicos, e perde-se a relação do que é "ensinado" em sala de aula com as necessidades de um pesquisador e profissional de psicologia.

Além disso, salvo algumas notáveis exceções, pouco se avança em termos da complexidade das técnicas ensinadas. O curso geralmente inicia com noções de delineamentos de pesquisa científica e depois aborda conceitos de probabilidade. Seguem-se aulas sobre estatística descritiva que incluem distribuição de frequências, cálculo e intervalos de confiança de médias e desvios-padrão. Por fim, chega-se às comparações de pares de médias com o teste $t$ de Student, às correlações bivariadas e, com sorte, ao qui-quadrado de Pearson. 0 semestre letivo encerra-se e, ao final, os alunos de graduação possuem um repertório básico de técnicas estatísticas. Procedimentos mais sofisticados, que viabilizem operações mais interessantes com os dados e que estejam presentes na maioria dos estudos nacionais e internacionais de qualidade, dificilmente são tratados em aula.

Análises fatoriais, regressão múltipla, correlações parciais, análises de variância com delineamentos de múltiplas variáveis e técnicas do gênero são vistas pela ampla maioria dos estudantes e futuros profissionais de psicologia brasileiros - e mesmo por um contingente expressivo de estudantes de pós-graduação e doutores - como recursos obscuros e misteriosos. Falta a muitos estudantes adquirir base de conhecimento para conhecer os fundamentos matemáticos dessas técnicas, que muitas vezes exigem um entendimento de assuntos ministrados em disciplinas de cursos superiores das áreas de ciências exatas. Talvez esse seja o motivo pelo qual os professores de estatística aplicada escolham não abordá-los em sala, uma vez que não chegariam a ser dominados a contento pelos estudantes de ciências psicológicas. Até o momento, poucos são os estudantes que têm acesso a essas técnicas, e isso ocorre apenas em disciplinas de estatística que constituem exceções

\footnotetext{
1 Dancey, C.P., \& Reidy, J. (2006). Estatística sem matemática para psicologia usando SPSS para Windows. Porto Alegre: Artes Médicas.

2 Universidade Federal de Santa Catarina, Departamento de Psicologia. Campus Universitário Trindade, 88040-900, Florianópolis, SC, Brasil. Correspondência para/Correspondence to: A.L. ANDRADE. E-mail: <alexsandro.deandrade@yahoo.com>.
} 
no cenário nacional. De modo geral, somente os estudantes que se aventuram em árduas empreitadas autodidatas ou realizam estudos de iniciação científica ou pós-graduação em laboratórios e núcleos de pesquisa de tradição quantitativa dominam esses conhecimentos.

É por esse motivo que a versão traduzida do livro de Dancey e Reidy, Estatística sem matemática para psicologia usando SPSS para Windows, é tão oportuna. Nas páginas iniciais, os autores argumentam que é possível ensinar técnicas estatísticas de modo conceitual, sem recorrer a fórmulas matemáticas pouca úteis para quem não domina esses conhecimentos.

Pode-se dizer que a obra possui quatro méritos que a diferenciam das demais publicações na área. $\mathrm{O}$ primeiro deles está na relação explícita com a psicologia, o que a torna altamente relevante para estudantes e pesquisadores. Todos os exemplos são provenientes de estudos verídicos dedicados a problemas atuais, o que possibilita ao leitor constatar a utilidade de cada técnica ou conceito para estudar fenômenos psicológicos. Um segundo ponto positivo reside na incorporação das instruções passo a passo no que diz respeito a como proceder para realizar as análises no pacote estatístico SPSS, provavelmente o mais popular dos programas estatísticos nos departamentos de psicologia brasileiros. Assim, o leitor que tiver acesso ao programa instrumentaliza-se para o uso das análises imediatamente após aprender conceitualmente sobre cada técnica ou teste.

Um terceiro ponto, e que constitui a principal vantagem do livro em relação a obras similares disponíveis no mercado brasileiro nacional, é que o leitor adquire um repertório de sofisticação considerável ao longo de suas 600 páginas, o que torna possível compreender a maior parte dos estudos com análises estatísticas de dados, bem como planejar e executar as próprias investigações com auxílio do SPSS.

Além dos capítulos usuais sobre planejamento de pesquisa, probabilidade, estatística descritiva e verificação de associação entre dados qualitativos e quantitativos, o leitor é apresentado a procedimentos antes encontrados apenas em materiais avançados de estatística. As análises de variância (ANOVA) com delineamentos fatoriais, técnicas essenciais para estudos experimentais, permitem comparar mais de dois grupos e analisar o efeito de duas ou mais variáveis independentes sobre variáveis dependentes. A análise de covariância (ANCOVA) possibilita verificar diferenças entre grupos a partir de uma variável quando se mantém constante o efeito de outra variável, denominada covariável. Está incluída também uma introdução à análise de variância multivariada (MANOVA), que permite avaliar diferenças entre médias envolvendo duas ou mais variáveis dependentes, bem como uma ou mais variáveis independentes. A regressão múltipla lida com a predição de variáveis a partir de outras. Destaca-se também um capítulo com introdução à análise fatorial, procedimento cujo objetivo central é a redução de um conjunto de variáveis a um grupo menor de fatores, bastante utilizada na construção de medidas psicológicas. Em síntese, os procedimentos são abordados com profundidade e grau de aplicação satisfatórios, incluindo considerações pertinentes acerca de quando podem ou não ser utilizados em análises de dados.

Finalmente, o quarto mérito do livro consiste em sua organização didática, com resumos e exercícios, o que o credencia como forte candidato a livro-texto de disciplinas de estatística de cursos nacionais. A obra tem potencial para facilitar e auxiliar na formação dos novos profissionais e pesquisadores brasileiros, preenchendo uma lacuna histórica da formação em psicologia.

Os autores demonstram que é possível tratar a estatística respeitando sua complexidade, apresentando conceitos e contextos de uso de modo extensivo e sem recorrer a macetes, promovendo o emprego responsável da estatística em pesquisa. A obra é pertinente também para pesquisadores que já possuam conhecimentos sobre estatística, afinal, os próprios autores admitem que as explicações que não se apóiam na matemática, por mais completas que sejam, sempre implicam a perda de alguma precisão em relação àquelas baseadas em demonstrações por meio de cálculos.

A proposta de Dancey e Reidy, e é a de uma estatística aplicada para pesquisadores compatível com os avanços tecnológicos que vêm permitindo a criação de programas de computador para executar rapidamente tarefas complexas de processamento de dados. Estatística sem matemática para psicologia usando SPSS para Windows é uma obra que torna palpáveis procedimentos considerados complexos, e pode ter impacto significativo para uma parcela importante de estudantes brasileiros. Não gostar de matemática não é mais desculpa para não usar estatística.

Recebido em: 5/1/2007 Aprovado em: 27/2/2007 